\title{
CHUVA ÁCIDA: UMA ANÁLISE DO CONHECIMENTO PRÉVIO DOS ALUNOS DO 3 ANO DO ENSINO MÉDIO NO MUNICÍPIO DE BOM JESUS DO ITABAPOANA (RJ) SOBRE O FENÔMENO
}

Leverson Ferreira Chaves ${ }^{1}$

Micaela Nicolite ${ }^{2}$

Roberta Almeida Cavichine ${ }^{3}$

Resumo: O fenômeno da chuva ácida é um problema ambiental que atinge muitos países do mundo com consequências para a saúde e o patrimônio público. Os Parâmetros Curriculares Nacionais sugerem que o conhecimento da Biologia deva estabelecer a cidadania e o potencial dos estudantes como agentes transformadores da sociedade, além de subsidiar o julgamento sobre o desenvolvimento, os recursos naturais e a intervenção humana no meio ambiente. Os resultados apresentados neste estudo com cento e trinta educandos do $3^{\circ}$ ano do Ensino Médio demonstraram que o fenômeno da chuva ácida é pouco compreendido pelos alunos e que as práticas podem ser ótimas ferramentas pedagógicas para elucidar essa questão ambiental.

Palavras-chave: Chuva ácida; Educação Ambiental; Ensino Médio; Bom Jesus do Itabapoana (RJ).

1 Universidade Federal do Rio de Janeiro. E-mail: leversonchaves@yahoo.com.br

2 Universidade Estadual do Norte Fluminense - Darcy Ribeiro. E-mail: micaela_uenf@yahoo.com.br

${ }^{3}$ Universidade Estadual do Norte Fluminense - Darcy Ribeiro. E-mail: cavicchi ne@hotmail.com 


\section{Introdução}

O fenômeno da chuva ácida é uma realidade em vários países do mundo, sendo caracterizado por valores muito baixos do $\mathrm{pH}$ (abaixo de 5,6) das águas pluviais em consequência do incremento de óxidos de nitrogênio e de enxofre oriundos principalmente de fontes antropogênicas e naturais (TOLENTINO et al., 2002); com prejuízos ao meio ambiente, ao patrimônio mundial e à saúde pública (GOULD, 1985; BAINES, 1997; MARTINS; MELLO, 2002; PIDWIRNY, 2006).

No Brasil, o fenômeno da chuva ácida ocorre sobre as maiores metrópoles do país, porém, com o aumento do parque industrial brasileiro e da frota de veículos (fontes antropogênicas dos óxidos de nitrogênio e de enxofre), o fenômeno ocorre em todas as regiões que recebem ventos de áreas industriais e de grandes metrópoles nacionais, sobretudo na Região Sudeste (FILHO et al., 1986; HUMERES, 1992; JESUS, 1999; BRENA, 2002; BRASIL, 2009).

O fenômeno da chuva ácida é reflexo da dinâmica da sociedade humana industrial. Assim, medidas que visem identificar e mitigar suas causas e consequências devem passar pela educação e pela sala de aula (MORIN, 2007). A educação forma um cidadão crítico, reflexivo e transformador das realidades socioambientais através dos conteúdos em sala de aula, apreensão da realidade e do contexto em que o aluno vive; intervindo na realidade e gerando novos saberes (FREIRE, 1996). Baines (1997), cita uma ação envolvendo estudantes suecos para mitigar o efeito da acidez em um lago em decorrência do fenômeno.

Nosso lago foi salvo pelos estudantes da cidade. Eles chegaram aqui para um trabalho de campo com seu professor e ficaram sabendo que antigamente o lago apresentava muitas formas de vida. Depois, tornou-se acidificado e muitas espécies estavam desaparecendo. As crianças queriam ajudar-nos a salvá-lo; então, voltaram no inverno e nos ajudaram a espalhar nove toneladas de cal sobre a superfície gelada do lago. Naquele verão, quando eles retornaram, mediram a acidez e verificaram que ela havia diminuído, passando o $\mathrm{pH}$ de 5,7 para 6,8. Eles trabalharam muito, mas pareciam divertir-se também e sentiram-se orgulhosos com o resultado obtido. Não poderíamos tê-lo feito tão depressa sem eles (BAINES, 1997, p.36).

Os Parâmetros Curriculares Nacionais (PCN) sugerem que 0 conhecimento da Biologia deva estabelecer a cidadania e o potencial dos estudantes como agentes transformadores da sociedade (Brasil, 2006); além de subsidiar o julgamento de questões polêmicas com respeito ao desenvolvimento, ao aproveitamento de recursos naturais e a utilização de tecnologias que impliquem intensa intervenção humana no ambiente (Brasil, 2002). Assim, é pertinente que os fenômenos ambientais decorrentes das 
ações antropogênicas, como o fenômeno da chuva ácida, sejam discutidos em sala de aula, gerando ações preventivas e mitigadoras das causas e consequências, além de desenvolver estudos, conter problemas e apresentar recursos alternativos através do dispositivo legal para o exercício de práticas pedagógicas condizentes com uma concepção progressista da educação (COELHO, 2005).

O objetivo geral deste estudo realizado em agosto de 2010 foi analisar como cento e trinta alunos do $3^{\circ}$ ano do Ensino Médio na cidade de Bom Jesus do Itabapoana (RJ) e seus distritos concebem o fenômeno da chuva ácida. Os objetivos específicos foram detectar equívocos e concepções prévias acerca do fenômeno, bem como se a aplicação de uma aula prático-teórica poderia elucidar a dinâmica e as consequências da chuva ácida.

\section{Materiais e Métodos}

Inicialmente foi realizado um levantamento nos colégios públicos e particulares do município de Bom Jesus do Itabapoana (RJ) e seus distritos, bem como dos alunos do $3^{\circ}$ ano do Ensino Médio, série na qual o conteúdo sobre o fenômeno da chuva ácida é abordado de acordo com as orientações curriculares para o Ensino Médio (BRASIL, 2006).

O levantamento demonstrou a existência de um escola federal, seis escolas estaduais e três escolas particulares que ofereciam o $3^{\circ}$ ano do Ensino Médio no município e seus distritos, com um total de 529 alunos distribuídos em 21 turmas (quinze públicas, quatro particulares e duas federais).

Para realizar a análise do conhecimento prévio dos alunos sobre o fenômeno da chuva ácida, determinou-se uma amostragem de aproximadamente $25 \%$ do total do número de alunos do $3^{\circ}$ Ano do Ensino Médio no município de Bom Jesus do Itabapoana (RJ) e seus distritos. Das escolas levantadas foram selecionadas para a realização da análise, sete turmas (duas públicas diurnas, duas públicas noturnas, duas particulares diurnas e uma integral) com um total de cento e trinta alunos. Não foram considerados os turnos, o período e o caráter público ou particular das escolas para a análise.

A análise para compor os resultados deste estudo foi baseada nas ideias centrais das questões discursivas e das respostas assinaladas pelos alunos nas questões objetivas. O período de duração da amostragem em cada turma foi de cem minutos (dois tempos de aula). Em todas as aulas ministradas o tempo de duração não foi excedido. Os alunos puderam escolher mais de uma alternativa nas questões objetivas.

A abordagem nas turmas para a análise foi realizada com uma apresentação pessoal, seguido de um esclarecimento sobre o objetivo da aula e a apresentação do tema "chuva ácida" nos primeiros cinco minutos de aula. A seguir foi aplicado um formulário (Formulário 1) com dez questões contendo perguntas objetivas e discursivas sobre o tema. Os alunos tiveram vinte 
minutos para responder as questões do Formulário 1. Uma aula prático-teórica foi ministrada (quarenta minutos de aula teórica e quinze minutos de aula prática) após a entrega do Formulário 1 por todos os alunos. Um novo formulário (Formulário 2) com onze questões mais elaboradas sobre o tema foi aplicado. Os alunos tiveram vinte minutos para responder ao Formulário 2. 0 objetivo de cada questão do Formulário 1 e do Formulário 2 se encontra na Tabela 1.

Tabela 1: Objetivo das questões realizadas nos formulários apresentados neste trabalho.

\begin{tabular}{|c|c|c|}
\hline Objetivo das questões & Formulário 1 & Formulário 2 \\
\hline $\begin{array}{l}\text { Identificar a noção básica do fenômeno pelos alunos e } \\
\text { sua primeira impressão do mesmo. }\end{array}$ & Questão 1 & Questão 1 \\
\hline $\begin{array}{l}\text { Identificar se o fenômeno é um assunto desconhecido, } \\
\text { pouco ou muito conhecido dos educandos. }\end{array}$ & Questão 2 & - \\
\hline $\begin{array}{l}\text { Identificar se os alunos concebem os locais de ocorrência } \\
\text { do fenômeno. }\end{array}$ & Questão 3 & Questão 2 \\
\hline $\begin{array}{l}\text { Perceber a distinção que os alunos fazem do fenômeno } \\
\text { em relação a outros fenômenos ambientais } \\
\text { antropogênicos. }\end{array}$ & Questão 4 & Questão 3 \\
\hline $\begin{array}{l}\text { Perceber se os alunos podem relacionar o fenômeno da } \\
\text { chuva ácida com ecossistemas naturais. }\end{array}$ & Questão 5 & Questão 4 \\
\hline $\begin{array}{l}\text { Verificar se os alunos possuem conhecimento das causas } \\
\text { naturais do fenômeno. }\end{array}$ & Questão 6 & Questão 5 \\
\hline $\begin{array}{l}\text { Saber se os alunos possuem algum conhecimento dos } \\
\text { países onde o fenômeno ocorre. }\end{array}$ & Questão 7 & Questão 6 \\
\hline $\begin{array}{l}\text { Observar o conhecimento dos alunos sobre os padrões } \\
\text { de acidez, escala de } \mathrm{pH} \text {, valores de } \mathrm{pH} \text { da chuva ácida e } \\
\text { da chuva normal. }\end{array}$ & Questão 8 & Questão 7 \\
\hline $\begin{array}{l}\text { Verificar se os alunos relacionam o fenômeno da chuva } \\
\text { ácida com áreas naturais. }\end{array}$ & Questão 9 & Questão 8 \\
\hline $\begin{array}{l}\text { Averiguar se os alunos podem formar os conceitos da } \\
\text { formação, dinâmica e efeitos do fenômeno da chuva } \\
\text { ácida através de imagens. }\end{array}$ & Questão 10 & Questão 9 \\
\hline $\begin{array}{l}\text { Verificar se uma aula prática sobre o fenômeno pode } \\
\text { ajudar os alunos a entender o mesmo. }\end{array}$ & - & Questão 10 \\
\hline $\begin{array}{l}\text { Perceber a visão dos educandos sobre a prevenção e } \\
\text { mitigação das causas e consequências do fenômeno da } \\
\text { chuva ácida. }\end{array}$ & - & Questão 11 \\
\hline
\end{tabular}

Fonte: Autoria própria. 


\section{Resultados}

Aos alunos foi indagado sobre "o que vinha à mente deles quando ouviam o termo chuva ácida". A maioria dos alunos tanto no Formulário 1 (vinte e nove alunos) quanto no Formulário 2 (trinta e sete alunos) associou a poluição ao fenômeno da chuva ácida. Um grande número de alunos (vinte e dois alunos) também caracterizou o fenômeno da chuva ácida como algo que corrói, corta, arde ou destrói. Este número diminuiu consideravelmente no Formulário 2 (três alunos).

A segunda pergunta realizada apenas no Formulário 1, inquiria os alunos se os mesmos já tinham ouvido falar do fenômeno da chuva ácida alguma vez em suas vidas. A Figura 1, demonstra que a maioria dos alunos $(43,8 \%)$ já tinham ouvido falar do fenômeno "muitas vezes".

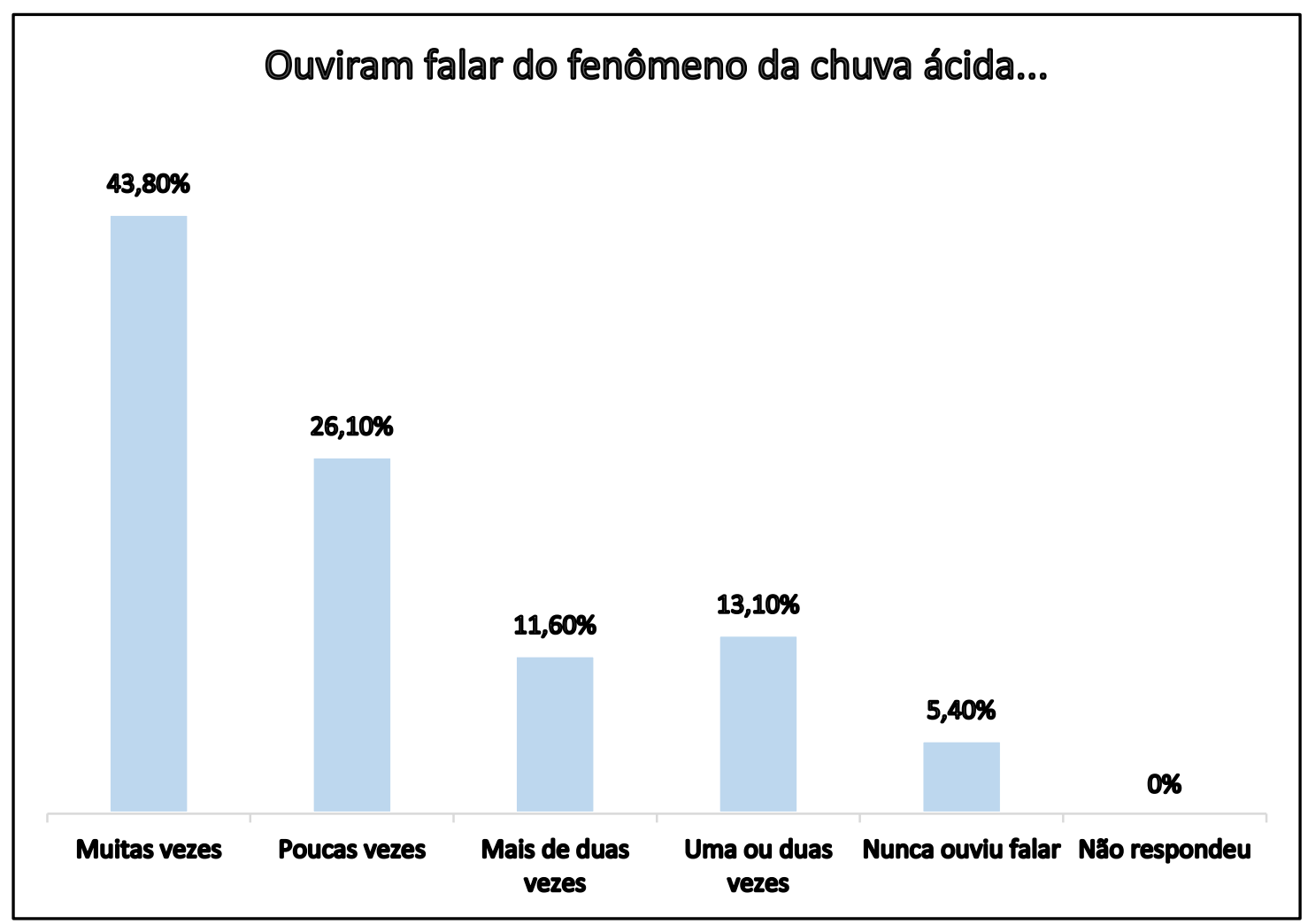

Figura 1: Porcentagem da frequência com que os alunos ouviram falar do fenômeno da chuva ácida. Fonte: Autoria própria.

Acerca do fenômeno da chuva ácida, foi perguntado aos alunos qual seu local de ocorrência. Dentre as alternativas, a maioria dos alunos disseram que o fenômeno ocorre em cidades com polos industriais locais.

Em resposta sobre a relação de alguns problemas ambientais de origem antropogênica com o fenômeno da chuva ácida, a maioria dos alunos 
(quarenta e três alunos no Formulário 1 e vinte e cinco alunos no Formulário 2) respondeu que o aquecimento global estaria relacionado com o fenômeno da chuva ácida. A opção "desmatamento, buraco na camada de ozônio e aquecimento global" foi a segunda alternativa mais escolhida pelos alunos no Formulário 1 (dezenove alunos). No Formulário 2, a segunda maior alternativa escolhida (dezoito alunos) foi "desmatamento, buraco na camada de ozônio, aquecimento global e desaparecimento de espécies".

Sobre os ecossistemas e a chuva ácida, foi indagado aos alunos quais ecossistemas apresentados no formulário, isto é, cidades, plantações, florestas, lagos, poderiam ser afetados pela chuva ácida. A maioria dos alunos escolheram a opção que afirma que todos os ecossistemas podem ser afetados, tanto no Formulário 1 (oitenta e um alunos) quanto no Formulário 2 (cento e dez alunos).

Sobre as prováveis causas da chuva ácida, foi solicitado aos alunos que optassem dentre as alternativas fornecidas, a saber, gases de erupção vulcânica, poluição industrial, gases de escapamentos de carros e "não sei", aquelas que corresponderiam a etiologia do fenômeno. A maioria dos alunos, tanto no Formulário 1 (sessenta e oito alunos) quanto no Formulário 2 (cento e onze alunos) escolheram todas as prováveis causas apresentadas nos formulários como sendo causas do fenômeno da chuva ácida. Apenas sete alunos no Formulário 1 e cinco no Formulário 2, optaram pela opção "gases de erupção vulcânica" apenas ou em conjunto com a opção "poluição industrial".

Acerca dos países onde há a ocorrência do fenômeno da chuva ácida, a Figura 2 apresenta a relação da frequência das respostas dos alunos quando solicitado aos mesmos que escolhessem as alternativas que correspondessem os países onde o fenômeno "não" ocorresse. A maioria dos alunos escolheu a opção "não sei" (cinquenta alunos) no Formulário 1. No Formulário 2, a maioria dos alunos (setenta e cinco alunos) escolheu a opção "nenhuma das respostas anteriores", seguido da opção "Noruega" (vinte alunos). No Formulário 1, a opção "Brasil" foi escolhida por dezoito alunos, considerando uma opção conjunta com "Canadá". No Formulário 2, a opção "Brasil" foi escolhida por dez alunos, considerando uma opção conjunta com "Noruega" e "Canadá". A opção "não sei" foi escolhida por trinta alunos no Formulário 1 e por dezoito alunos no Formulário 2. 


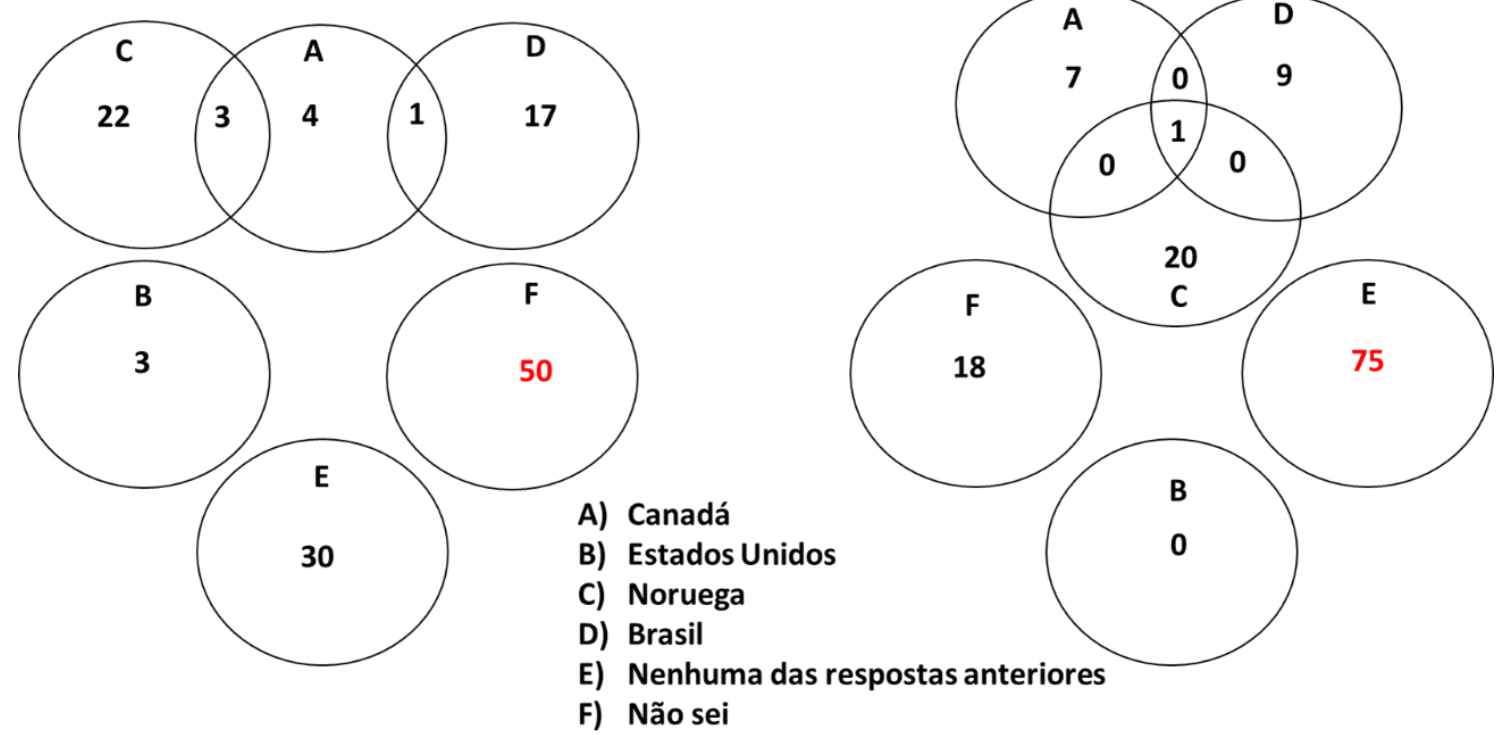

Figura 2: Relação do número de respostas dos alunos à questão: Qual destes países "não" apresenta chuva ácida? Fonte: Autoria própria.

Nos Formulários 1 e 2 foi solicitado que os alunos observassem uma figura contendo uma escala de $\mathrm{pH}$ (valores de 1 a 14) e identificassem os valores considerados para as águas de chuva como normal ou chuva ácida, justificando suas respostas. As respostas e ideias tais como, relacionar acidez aos sais, afirmar que o pH da chuva ácida é alto, ser ácida, ser mais quente, afirmar que o $\mathrm{pH}$ da chuva normal é 7 ou que a chuva normal é neutra foram consideradas como justificativas erradas. No Formulário 1, a maioria dos alunos (cinquenta e um alunos) errou os valores para chuva normal e acertou os valores para chuva ácida (cinquenta e nove alunos), porém cinquenta e oito alunos não justificaram suas respostas. No Formulário 2, a maioria dos alunos (sessenta e cinco alunos) acertou os valores para chuva normal, e oitenta e um alunos acertaram os valores para chuva ácida; porém, quarenta e quatro alunos não souberam justificar suas respostas. Um aumento do número de alunos que justificaram satisfatoriamente ocorreu do Formulário 1 (dezenove alunos) para o Formulário 2 (trinta e três alunos). Um aumento dos alunos que justificaram errado também ocorreu do Formulário 1 (quinze alunos) para o Formulário 2 (vinte e nove alunos).

Aos alunos foi perguntado se a evidência da ocorrência de chuva ácida na Floresta da Tijuca no Rio de Janeiro seria uma afirmação verdadeira ou falsa, e que justificassem suas respostas. A maioria dos alunos (cinquenta e cinco alunos no Formulário 1 e cento e três alunos no Formulário 2) concluiu que a afirmação é verdadeira. Os alunos que concluíram que a afirmação é falsa somaram quarenta e quatro alunos (quarenta e dois alunos no Formulário 1 e dois alunos no Formulário 2). Um total de cinquenta e oito alunos não respondeu à questão (trinta e três alunos no Formulário 1 e vinte e cinco alunos 
no Formulário 2). As justificativas para "falsa" e "verdadeira" dadas pelos alunos foram relacionadas na Tabela 2. Os alunos não fizeram nenhuma justificativa para "falso" no Formulário 2.

Tabela 2: Relação das justificativas se a evidência da ocorrência de chuva ácida na Floresta da Tijuca no Rio de Janeiro seria uma afirmação verdadeira ou falsa.

\begin{tabular}{|c|c|}
\hline FORMULARIO 1 & FORMULARIO 2 \\
\hline "VERDADEIRA" & $\begin{array}{c}\text { JUSTIFICATIVA PARA } \\
\text { "VERDADEIRA" }\end{array}$ \\
\hline Fenômeno global & Localização geográfica \\
\hline Gás carbônico elevado no Rio de Janeiro & Poluição industrial ge gases de autóveis \\
\hline Poluição industrial e de automóveis & A poluição viaja com as nuvens \\
\hline A floresta está sendo queimada pela chuva & Pesquisas apontam isso \\
\hline Muitos gases na camada de ozônio & "Palitificação" das árvores \\
\hline Leu nos jornais e meios de comunicação & - \\
\hline Porque lá chove muito & - \\
\hline Por causa dos incêndios na floresta & - \\
\hline A poluição viaja com as nuvens e se descola & - \\
\hline Por causa do aquecimento global & - \\
\hline Por causa dos danos a floresta & - \\
\hline JUSTIFICATIVA PARA & \\
"FALSA" & JUSTIFICATIVA PARA \\
"FALSA" \\
\hline Área de baixo risco & - \\
\hline Nunca ouvi falar & - \\
\hline Costuma ocorrer em cidades e não em florestas & - \\
\hline Não existe chuva ácida no Brasil & - \\
\hline Acima da floresta ou nela não ocorre chuva & - \\
ácida & - \\
\hline Porque só ocorre em plantações & - \\
\hline Senão a floresta já tinha morrido & - \\
\hline Não há evidência & - \\
\hline Porque o Rio de Janeiro é uma cidade litorânea & \\
\hline
\end{tabular}

Fonte: Autoria própria.

Algumas imagens, a saber, indústria com chaminés emitindo gases, estátua apresentando danos pela exposição à chuva ácida, fisionomia de árvores expostas constantemente à chuva ácida (paliteiros) e um esquema da dinâmica da formação do fenômeno foram colocadas nos formulários, sobre as quais foi indagado aos alunos o que essas imagens sugeririam a eles. A maioria dos alunos no Formulário 1 mencionaram que as imagens sugeririam as causas e consequências do fenômeno da chuva ácida, danos ao patrimônio público e desmatamento. No Formulário 2, os alunos mencionaram que as imagens sugeririam causas e consequências do fenômeno, danos ao patrimônio público e poluição.

No Formulário 2 apenas, foi inquirido aos alunos se a prática os ajudou a entender melhor o fenômeno e que justificassem suas respostas. As respostas foram apresentadas na Figura 3. Como justificativas para sim, os 
alunos mencionaram que com a prática, eles puderam visualizar as alterações do $\mathrm{pH}$, esclareceram e tiraram as dúvidas, que a prática esclareceu a teoria, que a linguagem da prática é clara, que puderam visualizar o que ocorre na atmosfera, que "não ficou somente na imaginação", que fez refletir, que imagens "ao vivo" são melhores para memorizar, "porque o professor interagiu com a turma", que fez algo complexo ficar simples de entender, que não sabia que o fenômeno era natural, "que a poluição fazia isso rápido" (acidez da água em tempo real), e que os gases poluentes eram tão perigosos.

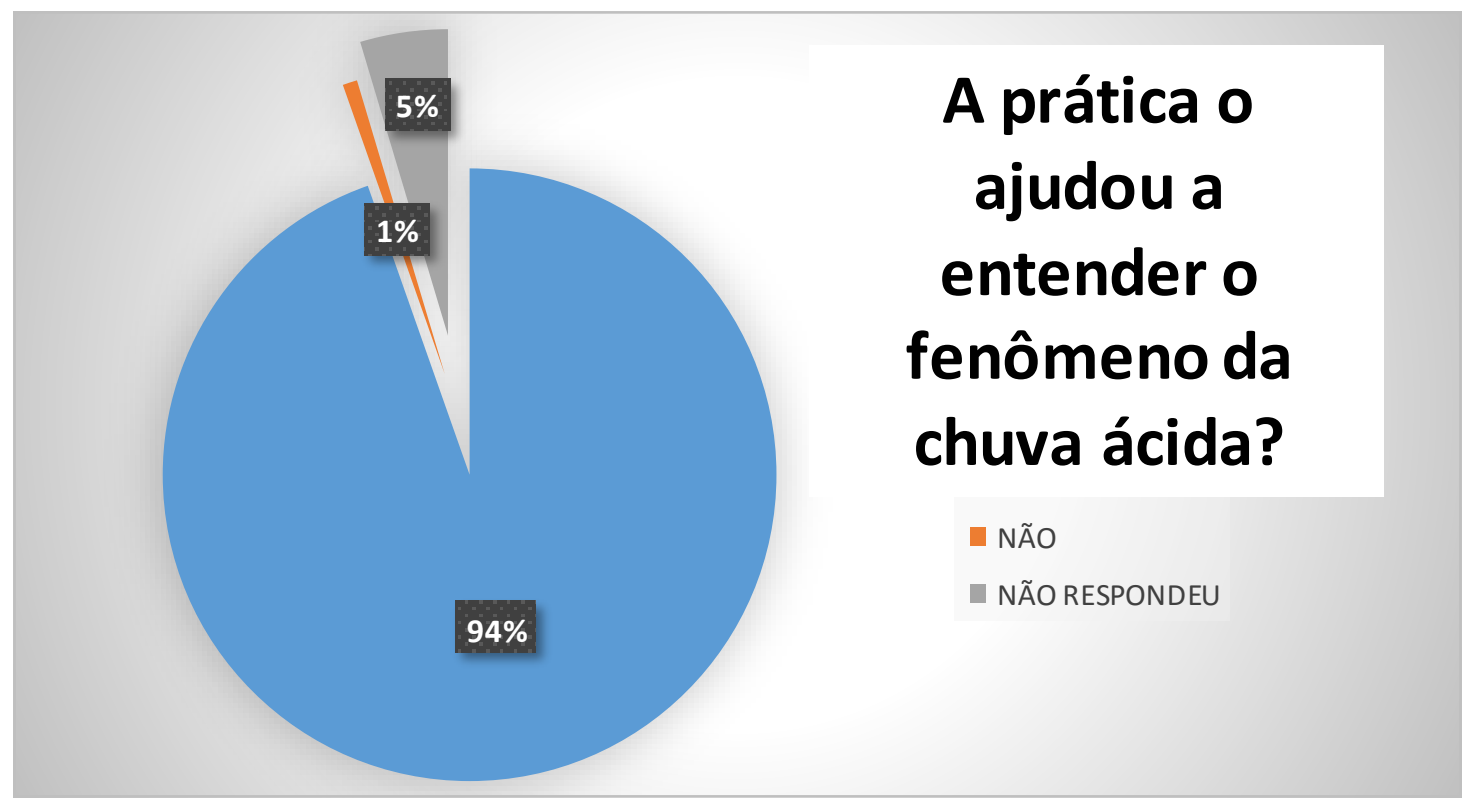

Figura 3: Porcentagem do número de alunos em resposta se a prática os ajudou a entender o fenômeno da chuva ácida. Fonte: Autoria própria.

Apenas no Formulário 2, foi solicitado aos alunos que dessem sugestões para que os problemas causados pelo fenômeno da chuva ácida sejam amenizados. Algumas das respostas dos alunos sugeriram "utilizar menos automóveis dando prioridade aos rodízios, bicicletas, carona e andar a pé"; "utilizar mais transportes públicos"; "não poluir"; "as fábricas devem utilizar filtros"; "controles e leis para que a poluição diminua"; "não desmatar"; "plantar árvores"; "tecnologias novas e renováveis"; "fazer revisões periódica de veículos"; "não queimar pneus"; "conscientização, fazendo cada um a sua parte"; "políticas públicas e governamentais"; "diminuir o consumismo"; "diminuição da poluição na camada de ozônio"; "utilização de combustíveis renováveis"; "utilizar menos combustíveis fósseis"; "sustentabilidade"; "preservar os ecossistemas e os recursos naturais; "acabar com os carros e destruir as indústrias; "evitar queimadas; "diminuir os agrotóxicos; "parar de chover; "jogar uma bomba nuclear nas cidades e indústrias.

Em uma análise geral dos resultados baseado nas respostas que obtiveram a maioria das escolhas assinaladas ou respondidas no Formulário 1 Revbea, São Paulo, V. 11, № 4: 226-242, 2016. 
e no Formulário 2, foi possível obter uma visão geral das escolhas feitas pelos alunos analisados (Tabela 3 ).

Tabela 3: Análise geral dos resultados baseado nas respostas que obtiveram a maioria das escolhas assinaladas ou respondidas pelos alunos nas questões do Formulário 1 e do Formulário 2.

\begin{tabular}{|c|c|c|}
\hline Questões & Formulário 1 & Formulário 2 \\
\hline $\begin{array}{l}\text { Pensam em poluição (gases, poluentes, tóxicos, outros) } \\
\text { quando ouvem o termo chuva ácida. }\end{array}$ & 29 alunos & 37 alunos \\
\hline Ouviram falar do fenômeno alguma vez. & Muitas vezes $(94,6 \%)$ & - \\
\hline $\begin{array}{l}\text { Associam o fenômeno da chuva ácida apenas às cidades } \\
\text { com polos industriais locais. }\end{array}$ & 104 alunos & 104 alunos \\
\hline $\begin{array}{l}\text { Afirmam que o aquecimento global está associado ao } \\
\text { fenômeno da chuva ácida. }\end{array}$ & 43 alunos & 25 alunos \\
\hline $\begin{array}{l}\text { Compreendem que os ecossistemas mencionados } \\
\text { (florestas, lagos, cidades e plantações) podem ser } \\
\text { afetados pelo fenômeno da chuva ácida. }\end{array}$ & 81 alunos & 110 alunos \\
\hline $\begin{array}{l}\text { Percebem todas as causas do fenômeno da chuva ácida, } \\
\text { tanto por fatores antropogênicos quanto por fatores } \\
\text { naturais. }\end{array}$ & 68 alunos & 110 alunos \\
\hline $\begin{array}{l}\text { Quais dentre os países citados (Canadá, Estados Unidos, } \\
\text { Noruega e Brasil) "não" apresentavam o fenômeno da } \\
\text { chuva ácida. }\end{array}$ & $\begin{array}{l}\text { Não sei } \\
\text { (50 alunos) }\end{array}$ & $\begin{array}{l}\text { Nenhum deles } \\
\text { (75 alunos) }\end{array}$ \\
\hline $\begin{array}{l}\text { Compreensão e justificação dos padrões de acidez } \\
\text { relacionados ao fenômeno da chuva ácida. }\end{array}$ & $\begin{array}{l}\text { Acertaram valores } \\
\text { para chuva ácida } \\
\text { (59 alunos) }\end{array}$ & $\begin{array}{l}\text { Acertaram valores } \\
\text { para chuva ácida } \\
\text { (81 alunos) }\end{array}$ \\
\hline $\begin{array}{l}\text { Consideraram a evidência de chuva ácida na Floresta da } \\
\text { Tijuca }\end{array}$ & $\begin{array}{c}\text { Verdadeiro } \\
\text { (55 alunos) } \\
\text { Falso } \\
\text { (42 alunos) }\end{array}$ & $\begin{array}{c}\text { Verdadeiro } \\
\text { (103 alunos) } \\
\text { Falso } \\
\text { (2 alunos) }\end{array}$ \\
\hline $\begin{array}{l}\text { Sugeriram satisfatoriamente que as imagens são as } \\
\text { causas e consequências do fenômeno da chuva ácida. }\end{array}$ & 15 alunos & 18 alunos \\
\hline $\begin{array}{l}\text { Escolheram a opção "sim" quando foi perguntado se a } \\
\text { aula prática os ajudou a entender o fenômeno da chuva } \\
\text { ácida. }\end{array}$ & - & $95 \%$ \\
\hline
\end{tabular}

Fonte: Autoria própria. 


\section{Discussão}

Quando foi perguntado aos estudantes "o que vinha a mente deles" quando ouviam o termo "chuva ácida", esperava-se que os alunos relatassem sua primeira impressão acerca do fenômeno (pergunta um do Formulário 1 e do Formulário 2). A maioria dos alunos relacionou o fenômeno com a poluição (gases, poluentes, tóxicos, outros) denotando que essa parece ser a percepção prévia dos estudantes. A acidez "como algo que arde ou derrete", mencionada pelos alunos, é um equívoco relacionado com a visão da natureza corrosiva de alguns compostos designados como ácidos, e não relacionado ao potencial hidrogeniônico $(\mathrm{pH})$ de uma solução. Este equívoco foi provavelmente sanado após a aula prático-teórica, baseado na queda do número de alunos que responderam desta forma no Formulário 2 (três alunos), ao contrário do número dos que responderam no Formulário 1 (vinte e dois alunos). Outros alunos (seis alunos no Formulário 2 e dois alunos no Formulário 1) ainda confundiram $\mathrm{pH}$ alto com $\mathrm{pH}$ ácido, demonstrando um certo desconhecimento sobre os termos relacionado ao $\mathrm{pH}$ e sua escala logarítmica. Uma parcela dos alunos (onze alunos no Formulário 1 e nove alunos no Formulário 2) citaram a "destruição de ecossistemas e patrimônio", demonstrando um entendimento dos efeitos do fenômeno.

Na pergunta dois do Formulário 1, a maioria dos alunos (43.8\%) ouviu falar muitas vezes acerca do fenômeno. Apenas $5,4 \%$ dos alunos (a minoria) nunca ouviram falar do mesmo, sugerindo que, apesar da pouca divulgação pública no Brasil acerca do fenômeno da chuva, os alunos parecem estar informados sobre o problema. É possível, entretanto, que esse conhecimento seja apenas relacionado ao tema, mas não à dinâmica e formação do fenômeno pelos equívocos e erros verificados neste trabalho.

A maioria dos alunos analisados (pergunta três do Formulário 1 e dois do Formulário 2) associa a ocorrência do fenômeno da chuva ácida às "cidades com polos industriais locais" (cento e quatro alunos no Formulário 1 e cento e quatro alunos no Formulário 2), provavelmente devido a associação que muitos fazem da poluição em grandes centros. Entretanto, a opção "ocorre em cidades com polos industriais locais e "apenas em áreas com vegetação natural" obteve um aumento evidente na escolha dos alunos após a aula prático-teórica (zero alunos no Formulário 1 e onze alunos no Formulário 2). Apesar da palavra "apenas" na frase "apenas em área de vegetação natural", talvez os alunos tenham percebido, após a aula prático-teórica principalmente, que áreas naturais também podem apresentar a ocorrência do fenômeno. Um pequeno aumento ocorreu no número de alunos que escolheram a opção "uma chuva qualquer" (dois alunos no Formulário 1 e quatro no Formulário 2) para caracterizar o fenômeno. Esses alunos talvez tenham confundido o fato que toda chuva apresenta valores baixos de $\mathrm{pH}$ ( $\mathrm{pH}$ em torno de 5,6), mas nem todas caracterizam o fenômeno da chuva ácida ( $\mathrm{pH}$ abaixo de 5,6).

A maioria dos alunos relacionou o "aquecimento global" de forma direta ao fenômeno da chuva ácida (quarenta e três alunos no Formulário 1 e vinte e cinco no Formulário 2), talvez pela relação do fenômeno com poluição $\left(\mathrm{CO}_{2}\right.$ Revbea, São Paulo, V. 11, № 4: 226-242, 2016. 
decorrente da queima de combustíveis fósseis). A opção "desaparecimento de espécies", que seria a opção certa, foi pouco escolhida pelos alunos.

Gouveia et al. (2009) realizaram uma pesquisa com noventa e um alunos em processo de conclusão do Ensino Médio da região metropolitana de Belo Horizonte (cinquenta alunos de escolas particulares e quarenta e um alunos de escolas públicas) com idade entre 17 e 23 anos. Ao serem indagados sobre os impactos ambientais que os alunos julgassem ser oriundos da queima de combustíveis fósseis, $15,9 \%$ dos alunos relacionaram a chuva ácida (3aㅡ opção mais escolhida) com a queima de combustíveis fósseis. Isto corrobora os dados presentes neste trabalho, que indicam que os alunos relacionam a poluição industrial ao fenômeno da chuva ácida. Gouveia et al. (2009) relatam que a maioria $(19,9 \%)$ dos alunos considerou o aquecimento global como causa da queima de combustíveis fósseis, corroborando a escolha dos alunos como um fenômeno relacionado à chuva ácida (poluição, tráfego de automóveis e queima de combustíveis fósseis) observadas no presente estudo.

Gouveia et al. (2009) também pesquisaram sobre quais impactos ambientais os educandos consideravam "mais graves". Segundo os autores, dos noventa e um alunos pesquisados apenas dois alunos jugaram a chuva ácida como grave. Isso também corrobora os dados obtidos neste trabalho, isto é, que os alunos conhecem o tema relacionado ao fenômeno da chuva ácida, mas desconhecem a dimensão da causa e das consequências do mesmo; muitas vezes relacionando o fenômeno diretamente ao aquecimento global, o qual é amplamente enfatizado na mídia brasileira em detrimento do fenômeno da chuva ácida. Os autores ainda afirmam que provavelmente o fenômeno da chuva ácida no Brasil não é considerada uma preocupação ou não faz parte do rol de informações envolvendo a ciência que mais veiculam na imprensa. $\mathrm{Na}$ pesquisa de Gouveia et al. (2009), a chuva ácida foi considerada pelos alunos pesquisados um impacto menos grave que o aquecimento global, a destruição da camada de ozônio, problemas respiratórios, os furacões e o derretimento das calotas polares, respectivamente.

Em relação a percepção dos alunos entre o fenômeno da chuva ácida com alguns ecossistemas naturais, a maioria dos alunos pesquisados compreendeu que todos os ecossistemas mencionados nos formulários podem ser afetados pelo fenômeno (oitenta e um alunos no Formulário 1 e cento e dez alunos no Formulário 2). A opção "cidades" foi amplamente escolhida, talvez pela visão prévia dos alunos de que o fenômeno pode ser causado pela poluição das cidades.

Os alunos analisados apresentaram conhecimento prévio acerca das causas naturais do fenômeno e perceberam as causas, tanto por fatores naturais quanto por fatores antropogênicos (sessenta e oito alunos no Formulário 1 e cento e onze no Formulário 2). No Formulário 1 a escolha pela opção "poluição industrial" (dezenove alunos no Formulário 1 e dois alunos no Formulário 2) refletiu a visão prévia dos alunos de que a poluição é a principal causa antropogênica do fenômeno em conjunto com a opção "gases de escapamento de automóveis" (vinte e um alunos no Formulário 1 e cinco no

revista brasileira educação ambiental 
Formulário 2). A opção "gases de uma erupção vulcânica" foi uma opção pouco escolhida, talvez por ser uma causa natural do fenômeno desconhecida dos alunos.

No século XX e no início do século XXI os problemas relacionados com a chuva ácida no mundo persistem e apresentam um aumento em vários países da Europa, Ásia, América do Norte e inclusive o Brasil (UNESCO, 1964; ZHAO; SUN, 1988; HUMERES, 1992; JESUS, 1999; BRENA, 2002, LISBOA, 2007). A maioria dos alunos analisados (cinquenta alunos no Formulário 1 e dezoito no Formulário 2) escolheu a opção "não sei" sobre o conhecimento dos países onde 0 fenômeno da chuva ácida ocorre, demonstrando desconhecimento sobre os países listados nos formulários. A opção "nenhuma das respostas anteriores" obteve o maior número de escolhas por parte dos alunos no Formulário 2 (setenta e cinco alunos), provavelmente com o auxílio da aula prático-teórica. Em relação aos outros países, as opções "Estados Unidos" e "Canadá" não foram escolhidos por um número considerável de alunos, talvez porque os alunos não reconheçam o fenômeno como um problema de países industrializados. A opção "Noruega" obteve o terceiro maior número de escolhas no Formulário 1 (vinte e dois alunos) e segundo maior no Formulário 2 (vinte alunos), talvez por ser um país pouco conhecido dos alunos. A opção "Brasil" (dezessete alunos no Formulário 1 e nove alunos no Formulário 2), talvez tenha sido pouco escolhida pela baixa repercussão sobre o fenômeno no país, ou ainda, pela visão de que o fenômeno não ocorra em países com florestas abundantes, como relatado na justificativa para falso (ocorrência da chuva ácida na Floresta da Tijuca) na Tabela 2.

É um consenso que as chuvas apresentem normalmente um $\mathrm{pH}$ baixo (por volta de 5,6), sendo, portanto, normalmente ácidas (MELLO; MOTTA, 1987; MIRLEAN et al., 2000; TOLENTINO et al., 2002); e caracterizando o fenômeno da chuva ácida em valores de águas pluviais com pH abaixo de 5,6. A maioria dos alunos analisados erraram os valores de $\mathrm{pH}$ das chuvas normais no Formulário 1, porém, acertando-os no Formulário 2. Em relação à chuva ácida, a maioria dos alunos analisados acertou os valores equivalentes à chuva ácida no Formulário 1, bem como no Formulário 2, auxiliados talvez pelo texto em inglês e pela aula prático-teórica. Entretanto, a maioria dos alunos não justificaram suas respostas tanto no Formulário 1 quanto no Formulário 2 (cinquenta e oito alunos no Formulário 1 e quarenta e quatro no Formulário 2), evidenciando uma carência dos alunos em elaborar os processos da dinâmica e da formação do fenômeno da chuva ácida, bem como a escala logarítmica do $\mathrm{pH}$ e sua relação com os termos ácido e básico.

Filho et al. (1986) constataram que a vegetação da Floresta da Tijuca, na cidade do Rio de Janeiro, era afetada pelos efeitos da chuva ácida. Ao serem indagados sobre essa afirmação, a maioria dos alunos considerou a afirmação verdadeira (cinquenta e cinco alunos no Formulário 1), porém um número expressivo de alunos considerou a afirmação como sendo falsa (quarenta e dois alunos no Formulário 1) ou não responderam à questão (trinta e três alunos no Formulário 1). Isso talvez demonstre um desconhecimento do 
fato por parte dos alunos, bem como equívocos acerca da ocorrência do fenômeno em áreas naturais e em países com áreas naturais abundantes, como o Brasil. A grande maioria considerou a afirmação como verdadeira no Formulário 2 (cento e três alunos). Com relação as justificativas apresentadas pelos alunos, foi possível verificar que os alunos analisados justificaram baseados na dinâmica do fenômeno, porém com alguns equívocos, como por exemplo, ao relacionarem o mesmo com o aquecimento global e $\mathrm{CO}_{2}$, camada de ozônio e defini-lo como "chuva que queima a floresta". As observações realizadas apontam para a falta de uma ampla divulgação do fenômeno das escolas e meios de comunicação. Justificativas como: "nunca ouvi falar", "não há evidência", "acima da floresta ou nela, não ocorre chuva ácida", "costuma ocorrer em cidades e não em florestas", "só ocorre em plantações", têm apontado para a falta de uma ampla divulgação do fenômeno nas escolas e meios de comunicação. Estas justificativas demonstram que alguns alunos analisados conhecem superficialmente ou não conhecem as causas, consequências e dinâmica do fenômeno da chuva ácida; e ainda relacionam diretamente o fenômeno ao aquecimento global e destruição da camada de ozônio.

Ferraz e Terrazzan (2001), acreditam que a linguagem, seja verbal, escrita, visual, gestual ou qualquer outra forma, permite ao ser humano expressar o seu pensamento. Através de imagens foi possível averiguar se os alunos poderiam formar os conceitos de formação, dinâmica e efeitos do fenômeno da chuva ácida. Os alunos sugeriram que as imagens lhes remeteram à poluição, consequências sobre o patrimônio público, chuva ácida e suas causas, bem como desmatamento. Da mesma forma, a maioria dos alunos (95\%) disseram que a prática os ajudou a entender o fenômeno da chuva ácida. Também foi possível perceber através das justificativas, tais como, "porque não sabia que a poluição fazia isso rápido", "imagens e ao vivo são melhores para memorizar", "fez algo complexo ficar simples de entender", que a prática é um excelente instrumento didático para gerar discussões, reflexões e contribuir para o entendimento e a visualização dos fenômenos que ocorrem em grande escala no meio ambiente (BRASIL, 2006).

Dentre as sugestões apresentadas pelos alunos para a prevenção e mitigação das causas e consequências do fenômeno da chuva ácida, podemos salientar: "o controle da poluição"; "utilização de transportes públicos"; "andar a pé ou de bicicleta"; "o rodízio de carros e carona"; "conscientização da população"; "diminuição do consumo"; "cuidado com os recursos naturais"; "criação de tecnologias e combustíveis renováveis"; dentre outras. Alternativas como: "acabar com os carros e destruir as indústrias"; "parar de chover" e "jogar uma bomba nuclear nas cidades e indústrias" foram muito incoerentes e demonstram a importância da educação para a conscientização dos alunos acerca do fenômeno no Brasil. 


\section{Conclusões}

A análise geral baseada nos dados que obtiveram a maioria das escolhas dos alunos nos Formulários 1 e 2, demonstraram que a "maioria" dos alunos analisados pensa em poluição quando ouvem o termo "chuva ácida".

A maioria dos alunos ouviu falar do fenômeno muitas vezes, e associa o mesmo apenas às cidades com polos industriais locais, demonstrando conhecerem que o fenômeno está diretamente ligado às ações humanas.

Os alunos analisados atribuem à poluição as causas do fenômeno da chuva ácida e parecem relacionar diretamente $\mathrm{o} \mathrm{CO}_{2}$ ao fenômeno. Além disso, os alunos costumam dar ao fenômeno um caráter urbano (o que ficou evidente na questão da Floresta da Tijuca), apesar de saberem que o problema pode ocorrer em outros ecossistemas, desconsiderando, porém, a maioria das suas causas naturais. A maioria também afirmou que o aquecimento global está associado ao fenômeno da chuva ácida e compreende, de forma básica, que os ecossistemas florestais (Floresta da Tijuca), lagos, cidades e plantações, podem ser afetadas pelo fenômeno da chuva ácida; além de perceber todas as causas do fenômeno da chuva ácida, tanto por fatores antropogênicos quanto por fatores naturais.

Os alunos analisados não têm conhecimento consolidado de que países como o Canadá, os Estados Unidos, a Noruega e o Brasil apresentam chuva ácida; mas a aula prático-teórica ajudou-os a entender isto. Um considerável número de alunos pareceu não conhecer quais deles apresentam o fenômeno da chuva ácida, incluindo o Brasil. Este desconhecimento provavelmente é virtude da baixa divulgação do fenômeno na mídia e nas escolas, apesar do tema fazer parte dos conteúdos. Neste último contexto, conclui-se que a aula prático-teórica auxiliou os alunos a aprofundarem seus conhecimentos sobre o tema.

A grande parte dos alunos analisados não souberam identificar padrões de acidez relacionados ao fenômeno da chuva normal, apesar da aula práticoteórica tê-los ajudado a identificar os valores de $\mathrm{pH}$ da chuva ácida e da chuva normal. A maioria também não conseguiu justificar suas respostas, indicando talvez um desconhecimento do processo químico da acidificação e não compreenderem as reações e padrões relacionados ao mesmo; bem como sua relação com a escala logarítmica do pH e os termos ácido e básico.

A análise geral demonstrou que os alunos utilizaram as imagens do formulário e a aula prática para elucidar sobre as causas e consequências do fenômeno da chuva ácida, bem como sua dinâmica. A maioria também afirmou que a aula prática os ajudou a entender o fenômeno.

Um apontamento mais específico sobre o conhecimento prévio dos alunos de turnos e períodos diferentes, ou ainda, dos alunos de escolas públicas em detrimento dos alunos de escolas particulares acerca do conhecimento do fenômeno da chuva ácida foi observado nas análises dos formulários. Estas observações não foram elencadas nos objetivos propostos 
nesse estudo, o que sugere a abordagem dos mesmos em trabalhos futuros relacionados à Educação Ambiental.

\section{Agradecimentos}

Aos docentes, discentes e direção de todas as escolas públicas e particulares do município de Bom Jesus do Itabapoana (RJ) e seus distritos pelo tempo cedido em sala de aula para a realização das práticas e do preenchimento dos formulários, através dos quais este estudo foi realizado.

\section{Referências}

BAINES, J. Chuva Ácida. 4ª edição. São Paulo. Scipione. 46p. 1997.

BRASIL. Ministério da Educação e Cultura. Secretaria de Educação Média e Tecnológica. Parâmetros Curriculares Nacionais (PCN). 360p. Brasília. 2002.

BRASIL. Ministério da Educação e do Desporto. Secretaria de Educação Média e Tecnológica. Secretaria de Educação Básica. Departamento de Políticas Públicas do Ensino Médio. Orientações Curriculares do Ensino Médio. Volume 2. 137p. Brasília, 2006.

BRASIL. Ministério das Cidades. Departamento Nacional Trânsito (DENATRAN). Registro Nacional de Veículos Automotores (RENAVAM). Brasília. 2009. Disponível em: http://www.denatran.gov.br/download/frota/FROTA 2009.zip, acesso em 16/06/2010.

BRENA, N.A. A chuva ácida e seus efeitos sobre as florestas. São Paulo. 68p. 2002.

COELHO, J.C. A chuva ácida na perspectiva de tema social: um estudo com professores de Química em Criciúma (SC). Santa Catarina. 2005.

FERRAZ, D.; TERRAZZAN, E. O uso de analogias como recurso didático por professores de biologia no ensino médio. Revista da ABRAPEC, $<$ www.nutes.ufri.br $>$. Rio de Janeiro. 2001.

FILHO, E.V.S.; OVALLE, A.R.C.; BROWN, I F. Precipitação ácida no Parque Nacional da Tijuca, Rio de Janeiro. Rio de Janeiro. Ciência e Cultura, v.39, n.4: pp.419 - 422, 1986.

FREIRE, P. Pedagogia da Autonomia. 36. ed. São Paulo. Paz e Terra. 1996.

GOULD, R. The science of acid rain. Boston. 1985.

GOUVEIA, V.P.; OLIVEIRA, S.R.; QUADROS, A.L. Algumas questões ambientais permeando o ensino de química: o que pensam os estudantes. Belo Horizonte. Ensaio, v.11, n.1: pp.1 - 22, 2009.

HUMERES, E. A chuva que não queremos. Ciência Hoje. Volume especial Eco-Brasil. 15-17. 1992. 
JESUS, E.R. A importância do estudo das chuvas ácidas no contexto da abordagem climatológica. São Paulo. 14:143-153. 1996.

LISBOA, H.M. Controle da Poluição Atmosférica: Efeitos causados pela poluição atmosférica. Santa Catarina. 34p. 2007.

MARTINS, C.R.; ANDRADE, J.B. Química Atmosférica do Enxofre IV: Emissões, Reações em fase aquosa e Impacto Ambiental. Bahia. Quim. Nova, v. 25, n.2, pp. 250-272, 2002.

MELLO, W.Z.; MOTTA, J.S.T. Acidez na Chuva. Ciência Hoje. São Paulo. V.6, n.34: pp.41-43, 1987.

MIRLEAN, N.; VANZ, A.; BAISCH, P. Níveis e origem da acidificação das chuvas na região do Rio Grande, RS. Rio Grande. Química Nova, v.5, n.23, pp.590-593, 2000.

MORIN, E. Os sete saberes necessários à educação do futuro. 12. ed. São Paulo. Cortez. 2007.

PIDWIRNY, M. Acid Precipitation: Fundamentals of Physical Geography. 2. ed. Viewer. 2006.

TOLENTINO, M.; ROCHA, R.; SILVA, R. 0 azul do planeta Terra: um retrato da atmosfera terrestre. São Paulo. 119p. 2002.

UNESCO. As chuvas ácidas: uma importação indesejada. Correio da UNESCO. Paris. 21-30. 1984.

ZHAO, D.; SUN, B. Acid Rain in Southwestern China. Atmos. Environ, v.22: pp.349-358, 1988. 